\title{
Anxiety Disorders
}

\author{
Paul T E Cusack* \\ 23 Park Ave. Saint john, Canada \\ Corresponding author: Paul TE Cusack, 23 Park Ave, Saint john, NB, Canada
}

\begin{tabular}{|c|c|}
\hline ARTICLE INFO & ABSTRACT \\
\hline $\begin{array}{l}\text { Received: 幽 October } 13,2020 \\
\text { Published: 蔧 October 29, } 2020\end{array}$ & $\begin{array}{l}\text { In this paper, we show how the chemistry of stress build up in the body can lead to } \\
\text { anxiety and other illnesses. Anxiety is at the heart of many other mental illnesses and } \\
\text { disorders. }\end{array}$ \\
\hline $\begin{array}{l}\text { Citation: Paul T E Cusack. On Pain. Anxiety } \\
\text { Disorders. Biomed J Sci \& Tech Res 31(3)- } \\
\text { 2020. BJSTR. MS.ID.005107. }\end{array}$ & $\begin{array}{l}\text { Keywords: Anxiety; OCD; Schizophrenia; Bipolar; PTSD, Chronic Fatigue; Phobias, Hypo- } \\
\text { chondria; Maslow's Hierarchy; Stress; Cortisol; Testosterone; Sense; Smell; Taste }\end{array}$ \\
\hline
\end{tabular}

\section{Introduction}

I have noticed that those with Obsessive-Compulsive and Anxiety Disorders do not have children, nor are they married. None exercise. I theorize that it is caused by a lack of release of sexual tension and or a lack of physical exercise. Not having children may be partly the psychological cause too. In this brief paper, I consider the release of testosterone, present in both men and women, that may lead to anxiety. We will consider how anxiety plays a key role in a variety of mental health problems. Stress release is paramount in healing from anxiety. The hormone involved in the sexual drive is testosterone. It has a molecular mass of $288.42 \mathrm{gm} / \mathrm{mol}[1,2]$.

$$
\begin{aligned}
& M=\operatorname{Ln} t \\
& 288.42=\operatorname{Ln} t \\
& t=1.816
\end{aligned}
$$

\section{Golden Mean Parabola}

$$
\begin{aligned}
& t^{\wedge} 2-t-1=E \\
& E=4818 \\
& 1 / t=E=207.5 \\
& E=1366-207.5=115.9 \\
& E^{\wedge} 2+E-2=502=1 / 2=t \text { min }
\end{aligned}
$$

This implies SE=SE'

$\mathrm{t}^{\wedge} 2-\mathrm{t}-1=2 \mathrm{t}-1$

\section{$E=5 ; t=3$}

$\sin 45=\cos 45$

The sine curve represents stress causing anxiety and the cosine represents relaxation or sexual tension release.

This is the maximum point where $\sin +\cos =$ sqrt 2 . The green line is $(\sin +\cos )$ (Figure 1$)$.

\section{Euler's Identity}

$\operatorname{Sin}^{\wedge} 2 t+\cos ^{\wedge} 2 t=1$

$\operatorname{Sin}^{\wedge} 2(45)+\cos ^{\wedge} 2(45)=1$

\section{Universe Meets Mind Equation}

$\mathrm{Y}=0.0516 \mathrm{t}+0.948=1$

$1-0.948=0.0516 \mathrm{t}$

$\mathrm{t}=1$ (Figure 2)

$E=(1-\ln t)^{3}$

Note: This is to the power 3 instead of 7 for the Hippocampus which has only three layers of nerve cells- not 7.

$(\sqrt{3})^{1 / 3}=(1-\operatorname{Ln} t)$

$1.2=1-\mathrm{Ln} \mathrm{t}$ (olfactory receptor cells density $=12 \mathrm{M} / 10 \mathrm{~cm}^{\wedge} 2=1.2$ for humans)

$0.2=\operatorname{Ln} t$ 
$\mathrm{t}=\mathrm{e}^{0.2}=7.389$

GMP: 37.2

\section{$0.268=\mathrm{SF}$}

The limbic system, or the emotional brain, is deep in the centre of the brain and is more predated the development of the cortex. The sense of smell is hard wired into the limbic system. The limbic system is involved in the fight or flight response, mating, and finding food. The limbic system is privy to all the sensory information coming into the brain. It makes sense that the sense of smell is tied to the limbic system at sqrt3. This is when time $=1$, and $y=2$
( $\mathrm{SE}=\mathrm{SE}$ ') (Figure 3). The limbic system is involved with the bottom three of Maslow's Hierarchy of Needs -survival of the species. Chronic Fatigue Syndrome may be caused by an incessant response to stress. Perhaps it is related to Post Traumatic Stress Disorder. The stress leads to phobias and hypochondria. So the key is stress and relaxation which are modelled by the sine and cosine curves. Peter has anxiety, hypochondria, and phobias from unemployment, bullying and physical and mental injuries. John has Anxiety because of trouble with the law. Mary has Anxiety over bereavement. Geordie has OCS and anxiety because of bullying. Brian has OCD because he is a perfectionist. Ben has PTSD from witnessing a dead body. There is an exterior reason for their mental illnesses (Figure 4).

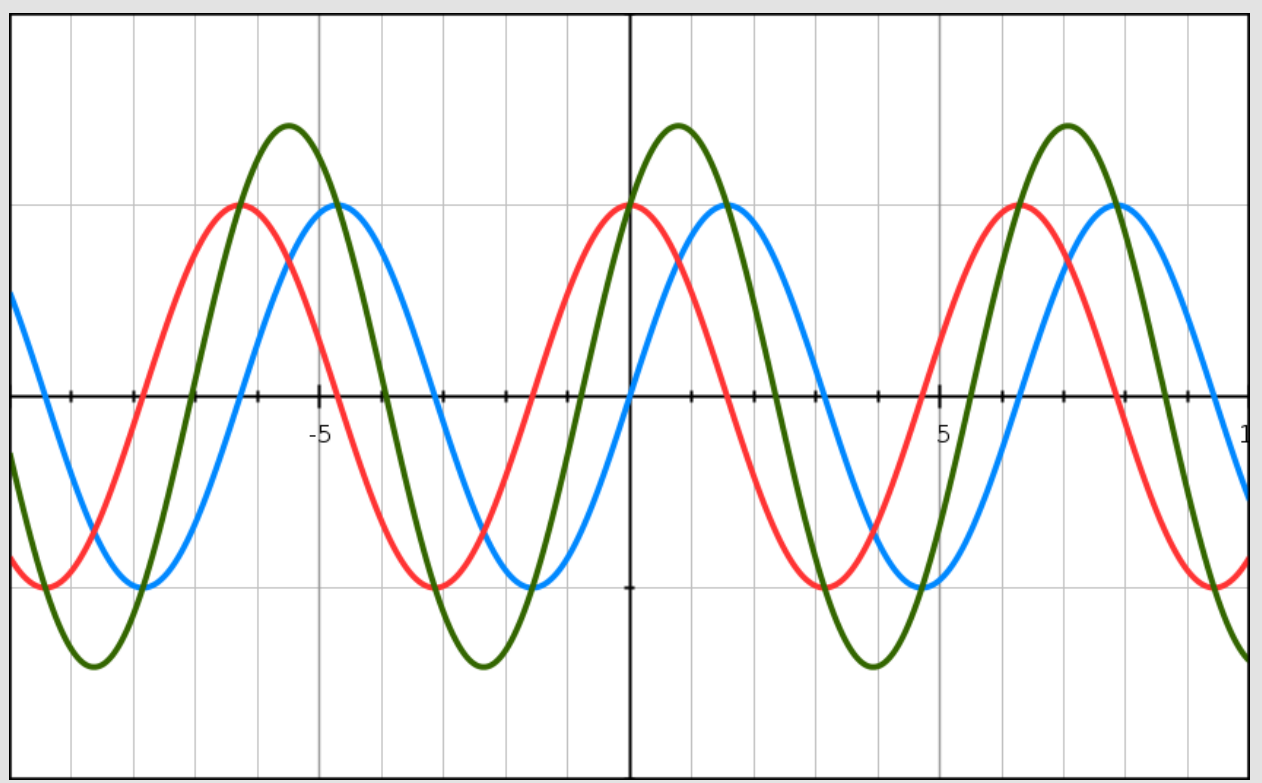

Figure 1: $\operatorname{Sin}$ and cons; $\operatorname{Sin}+\cos$.

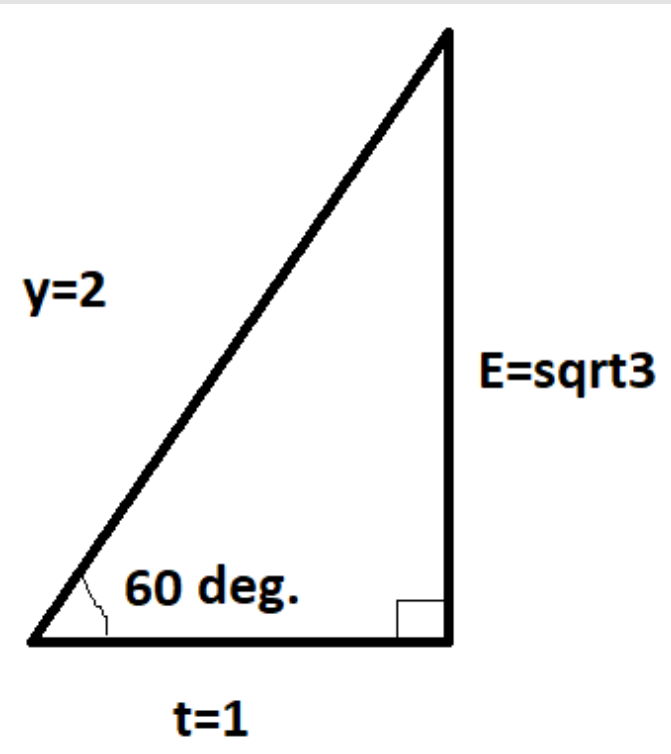

Figure 2: 30-60-90 triangle. 


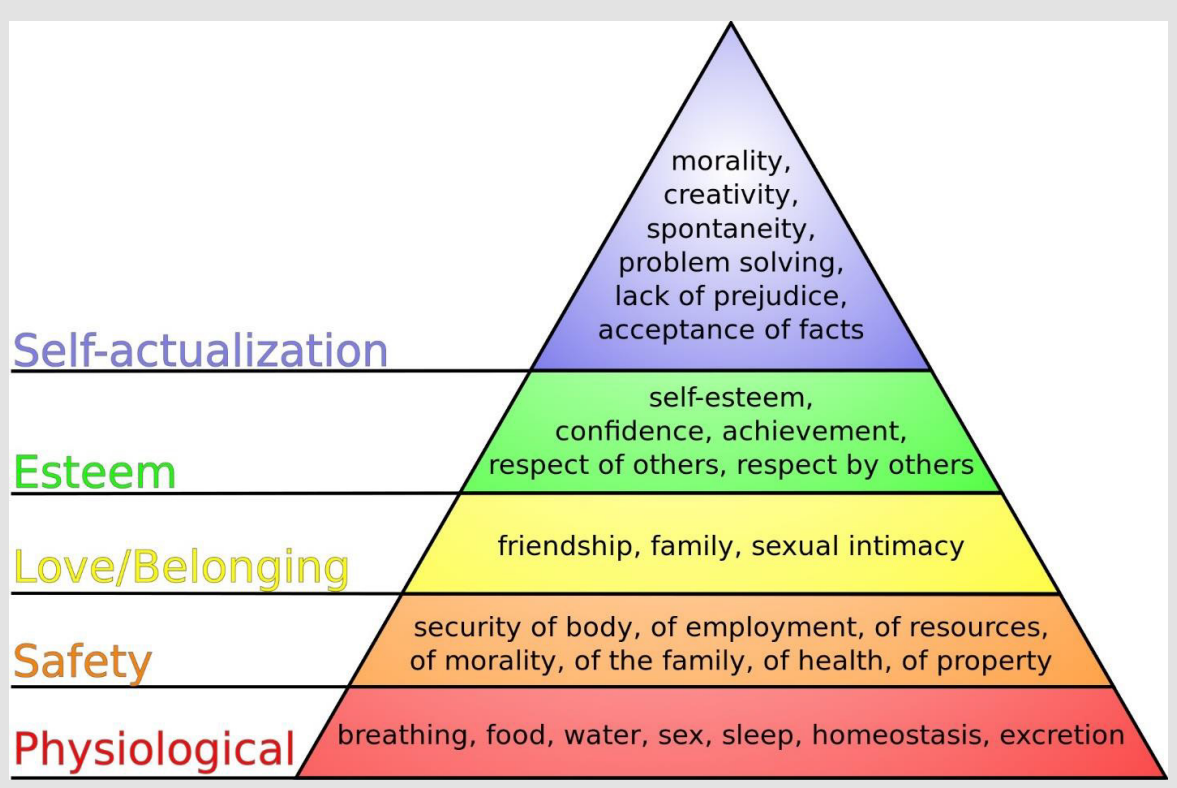

Figure 3: Maslow's Hierarchy of Needs.

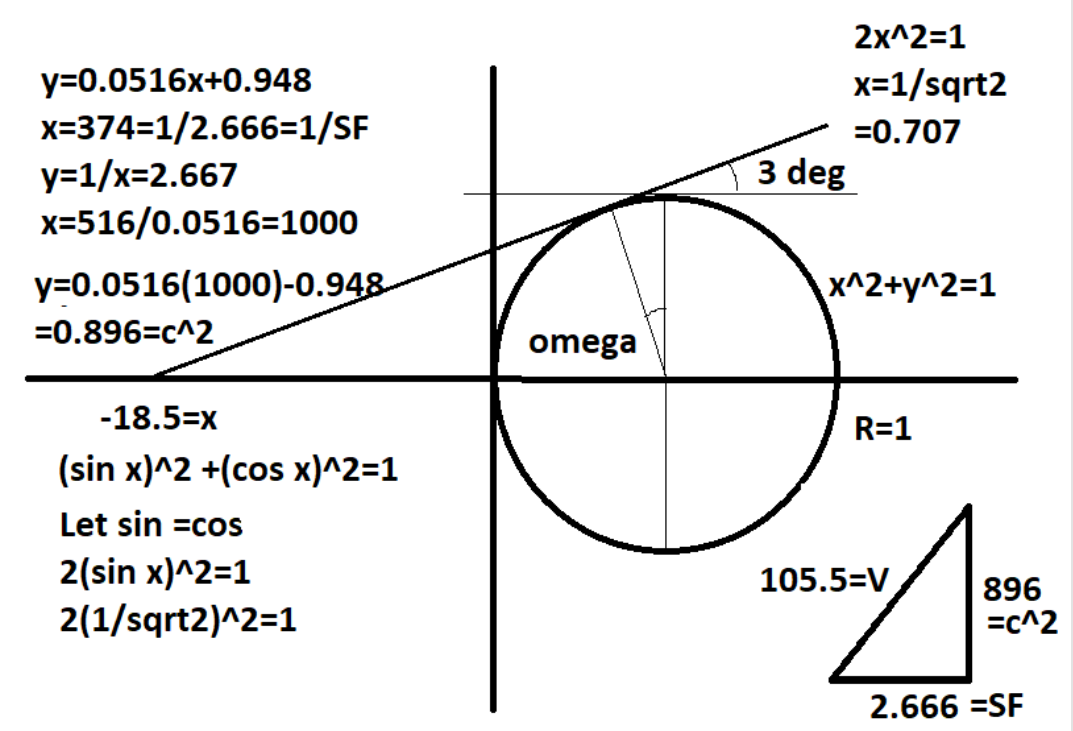

Figure 4: Universe meets mind equation.

$$
\begin{aligned}
& 3^{\circ}=0.05235 \mathrm{rads} \\
& 0.05235 / 2 \pi=0.08333 \\
& \alpha=\omega^{2} \mathrm{R} \\
& =(1 / 12)(1) \\
& =1 / 144=0.693 \sim \operatorname{Ln} 2 \\
& \mathrm{~F}=\mathrm{Ma}
\end{aligned}
$$$$
0.05235 / 2 \pi=0.083333=1 / 12 \text { of a cycle }
$$$$
2.667=\mathrm{M}(0.693)
$$

$\mathrm{M}=384$

$\mathrm{M}=\operatorname{Ln} \mathrm{t}$
$384=\operatorname{Ln} \mathrm{t}$

$\mathrm{t}=1468=1 / 681$

Serotonin + Tryptophan $\rightarrow$ Testosterone $++\Delta \mathrm{Q}$

$176.21+204.23=288.47+\Delta Q$

$\Delta q=91.97 \sim 92$

$92 \times 6.023=554$

$\mathrm{e} 0.554=1.7228 \sim \sqrt{3}$

$\mathrm{S}=\Delta \mathrm{Q} / \mathrm{T}$

$=91.97 /(273.15+37)=296.5 \sim 297 \sim c$ 


$91.97 \times(3.14159)=28$
Sine $=$ cosine
Immunity =Contagion
$\cos \theta=\sin \theta$
$M v=1 / t$
$\operatorname{Ln} t(1 / \sqrt{2})=1 / t$
$(1 / \sqrt{2}) \operatorname{Ln} t=1 / t$
$(1 / \sqrt{2}) y=y^{\prime}$
$\sqrt{2} y=y^{\prime}$
$\int \sqrt{2} y=\int y$
$(\sqrt{2}) y^{2} / 2=y$
$1 / \sqrt{2} \times y=1$

$\mathrm{y}=\sqrt{2}$

$\sin \theta+\cos \theta$

$=\sin 45+\cos 45=$

$=(1 / \sqrt{2})+(1 / \sqrt{2})$

$=2 / \sqrt{ } 2$

$\mathrm{E}=\sqrt{2}=\max$ of $\sin +\cos$

I have experience with a variety of mental illnesses. Some I have suffered myself; others in people I knew. Figure 3 illustrates have they may be interrelated. At the heart of them all is stress (Figure 5). My hypothesis is that a lack of sexual hormone release (testosterone) causes the stress hormone Cortisol to increase in the system. Of course, testosterone is made from tryptophan and serotonin. with a cofactor iron. We provide the chemical mole balance here:

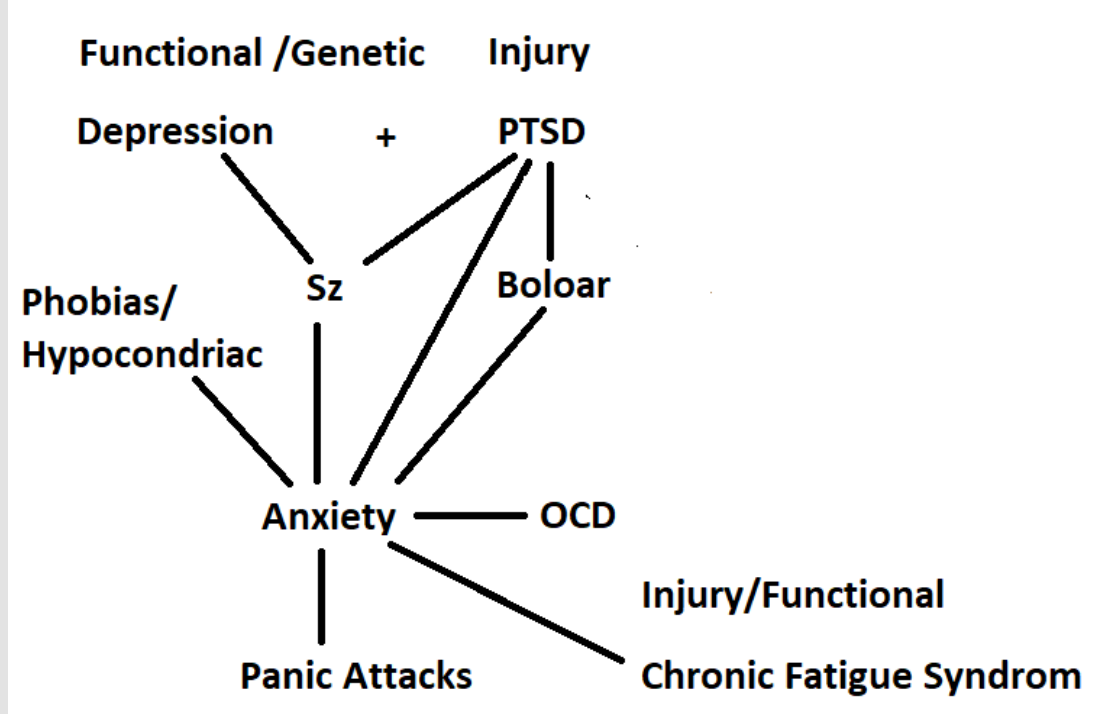

Figure 5: Functional, Genetic and Injuries to the brain.

$\mathrm{C}_{10} \mathrm{H}_{12} \mathrm{~N}_{20}+\mathrm{C}_{11} \mathrm{H}_{12} \mathrm{~N}_{2} \mathrm{O}_{2}+\mathrm{Fe}_{2} \mathrm{O}_{3} \rightarrow \mathrm{C}_{19} \mathrm{H}_{28} \mathrm{O}_{2}+2 \mathrm{CH}_{2}+\mathrm{Fe}_{2} \mathrm{O}_{3}+2 \mathrm{O}_{2}$

Serotonin (176.215g/mol.) +Tryptophan (204.22) + Cofactor $(159.69) \rightarrow$ Testosterone (288.43)+Methane (28) + Ferric Oxide (159.69) + Oxygen (64)

$$
\rightarrow \mathrm{C}_{19} \mathrm{H}_{28} \mathrm{O}_{2}+\mathrm{C}_{21} \mathrm{H}_{30} \mathrm{O}_{5}+2 \mathrm{CH}_{2}+\mathrm{Fe}_{2} \mathrm{O}_{3}+1 / 2 \mathrm{O}_{2}
$$

Testosterone (288.43) + Cortisol (362.46) +(28)+(159.69)|+(16)

$$
\rightarrow \mathrm{C}_{42} \mathrm{H}_{62} \mathrm{H}_{11}
$$

Sugar (742.4292)

$176.215+204.22+159.69=540.125$

$288.43+28+159.69+64=540.125$

$\mathrm{M}=\mathrm{Ln} \mathrm{t}$
$540.125=\operatorname{Ln} \mathrm{t}$

$t=--1.242$

$\mathrm{M}=\operatorname{Ln} \mathrm{t}$

$742.4292=\operatorname{Ln} t$

$t=21.01$

$1 / \mathrm{t}=-1.249 \sim-1.25 \Rightarrow$ GMP

Taste and smell are closely linked.

There are 8 primary odors. $1 / 8=-1.25=$ Emin

There are 5 primary tastes. GMP E= 5 ; $\mathrm{t}=3$

Taste + Smell energy $=5+1.25=62.5 \times 2$ pairs $=1.25$ 


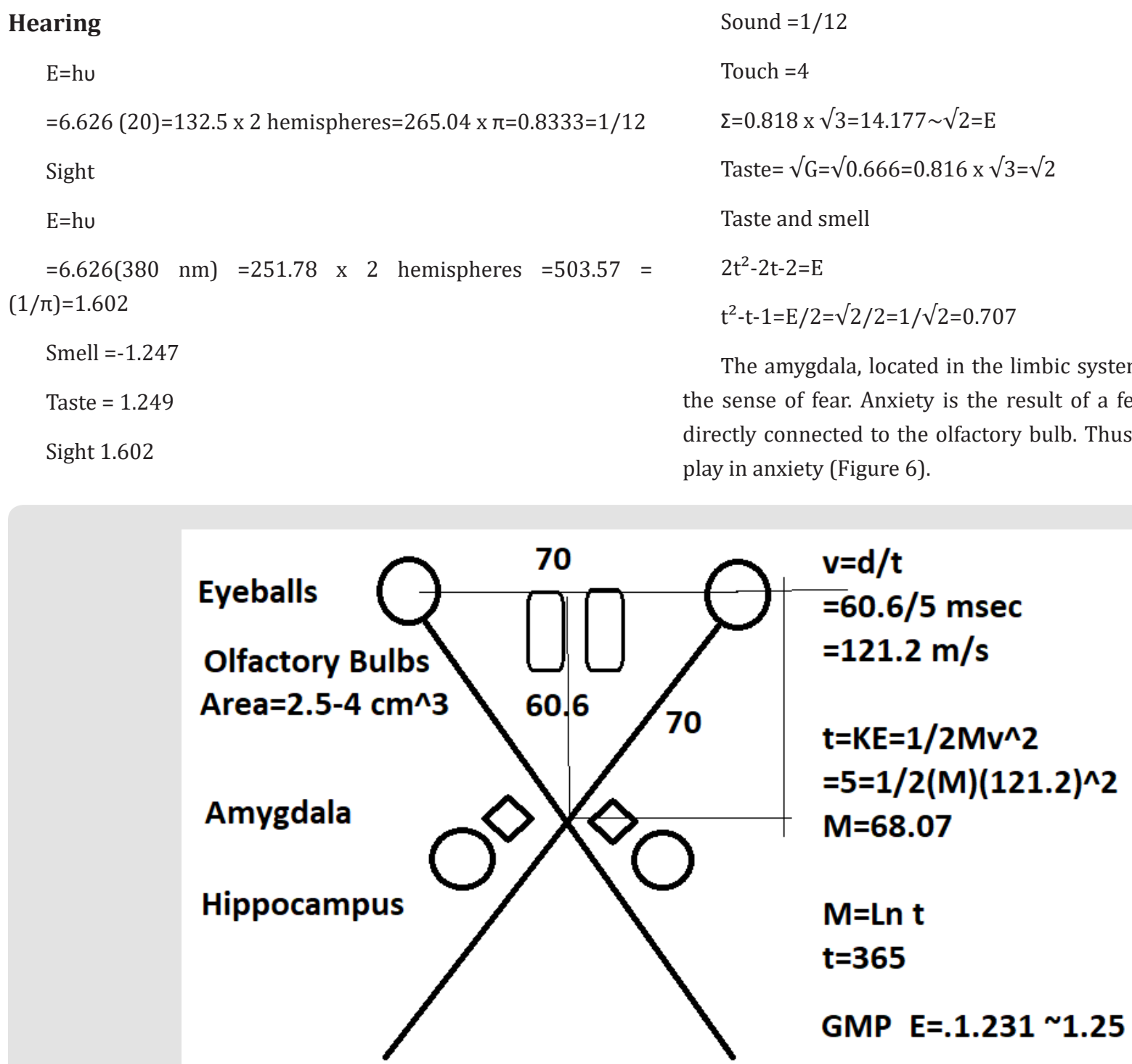

Figure 6: Olfactory Bulb.

\section{Bottom Up - Senses}

$$
\begin{aligned}
& V=i R \\
& i=t^{2} \\
& 105 m V=t^{2}(1) \\
& t=1024 \\
& E=(1-\operatorname{Ln} t)^{7} \\
& =(1-\operatorname{Ln} 10.247)^{7} \\
& =369.5 \\
& 1 / E=t=27067 \sim e^{1} \\
& E=e^{-1}
\end{aligned}
$$

Top Down - Memories

$\mathrm{SE}=\mathrm{E} \cdot \mathrm{M}$
$=(-1 / 8) \cdot(1 / 9)=-1 / 72$

$\mathrm{E}=\mathrm{hu}$

$(-1 / 7.2)=6.626 u$

$u=-47.7$

$1 / \mathrm{u}=$ Period $\mathrm{T}=-209.6$

$\mathrm{t}=-47.7$

$\mathrm{E}=-(1-\operatorname{Ln} 47.7)^{7}$

$=1584.7 \sim$ Moment

$\mathrm{Mom}=\mathrm{F} \times \mathrm{d}$

$\mathrm{F}=8 / 3=2.666$

$\mathrm{Fd}=2.667 \mathrm{~d}=0.1585$

$\mathrm{d}=0.594 \sim 6$ 


$$
\begin{aligned}
& E=1 / t=1 / s \text { since } t=s \\
& E=159 \\
& t=1 / 159=6.28=1 \text { cycle }
\end{aligned}
$$

The freq of the human brain $=1 / \pi$

$$
\begin{aligned}
& 2 \pi \times 1 / \pi=2 \\
& 2^{2}-2-1=E=1 \\
& E=t=1 \\
& y=0.0516 x+0.948 \\
& y^{\prime}=0.0516
\end{aligned}
$$

\section{ISSN: 2574-1241}

DOI: 10.26717/BJSTR.2020.31.005107

Paul T E Cusack. Biomed J Sci \& Tech Res

(C) (i) This work is licensed under Creative

Submission Link: https://biomedres.us/submit-manuscript.php

$$
\begin{aligned}
& y=y^{\prime} \\
& 0.0516=0.0516 x+.948 \\
& x=17.32=10 \sqrt{3} \alpha \sqrt{3}=t
\end{aligned}
$$

\section{Conclusion}

Stress causes a host of mental illnesses and disorders. We see that a buildup of stress, including sexual, leads to anxiety driven illnesses. Anxiety is at the heart of many other mental illnesses and disorders.

\section{References}

1. Carter R (2011) The Human Brain Book. Penguin, Oxford, USA.

2. Diamond MD (1985) The Human Brain Coloring Book. Collins, USA.

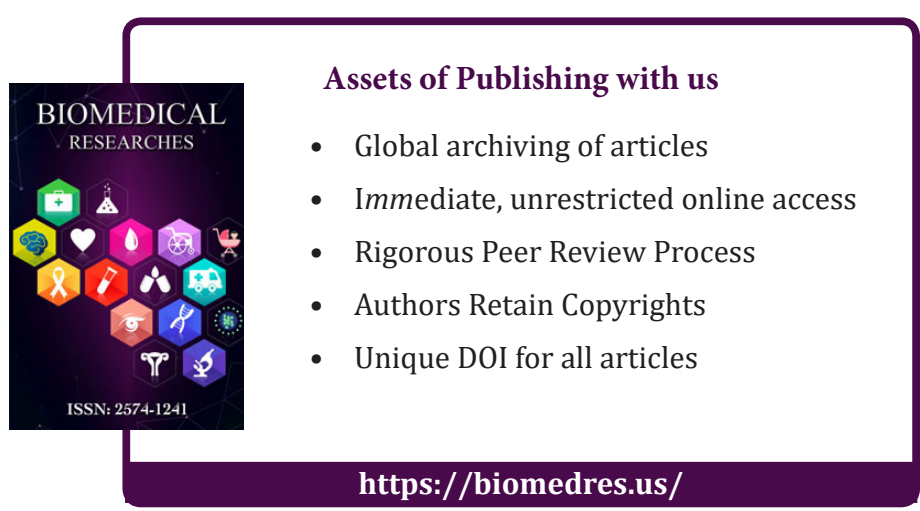

